\title{
Por Quem os Sinos Dobram: O Leading Case das Queimadas no RS
}

\section{Patricia Azevedo da Silveira}

\author{
Mestre em Direito Público - UFRGS \\ Doutoranda em Direito / UFRGS \\ Professora de Teoria Constitucional do Direito Ambiental do Curso de \\ Especialização em Direito Ambiental da UFRGS \\ Vicente de Azevedo Marques \\ Mestre em Integração da América Latina - USP \\ Assessor Técnico da Assembléia Legislativa - RS
}

APRESENTAÇ̃̃O 1. Sob fogo cruzado: as queimadas na atena parlamentar gaúcha $2 \mathrm{Da}$ Constituição Estadual à Emenda Constitucional 32/2002: uma cronologia 3. A Emenda Constitucional $32 / 02$ e a atuação do Ministétio Público 4 . As queimadas na jurisprudência do TJRS CONCLUSÃO BIBLIOGRAFIA

\section{Apresentação}

$O$ direito ambiental no Brasil vem sendo paulatinamente implementado. Em sível infraconstitucional, a Lei 6.938/81, que dispõe sobre a Política Nacional de Meio Ambiente, sinalizou pela primeira vez de forma profunda, a busca de um novo paradigma na relação homem-natureza, sobretudo no que diz respeito à aproptiação dos bens ambientais. Embora inúmeras metas tenham sido elaboradas na Rio-92, constatou-se que elas não foram efetivamente concretizadas. $O$ diagnóstico atual não é nuito animador, pois não vivemos num estágio de desenvolvimento sustentável. 
É natural que num processo de elaboração das leis, uma "avalanche verde" de normas restritivas sejam criadas para suprir uma lacuna normativa existente. Num segundo momento, quando as restrições começam a ser vividas por segmentos produtivos, percebe-se o descompasso entre norma e realidade pelas mais diversas razões.

Muitas vezes essa saida é o não-cumprimento das normas existentes. Noutras, a opção é tentar mudar as normas. Mas num regime que proclama uma Constituição rígida, seu conteúdo deve ser devidamente apreciado para se verificat o que efetivamente pode ser alterado. Caso contrário, estaríamos violando o Estado de Direito. Mesmo em nível infraconstitucional não podemos perder de vista o horizonte constitucional que invoca a delineação axiológica dessa categoria de normas. Caso contrário, poderemos estar criando uma lei arbitrária ${ }^{1}$.

O sistema da repartição de competências previsto na Constituição Federal (CRFB) de 1988 dispõe que em matéria ambiental a competência para legislar é concorrente, com fulcro no artigo 24, VI. Isso significa dizer que a União edita normas gerais e os demais entes da federação a complementam adequando-as às suas peculiaridades regionais e locais. Mas essa norma há de ser geral, sob pena de infringir o campo de autonomia que o regime federativo reconhece aos demais entes da federação.

Não há um dispositivo na CRFB que autorize as queimadas. Na Constituição gaúcha de 1989 há a sua vedação expressa (art. $251, \$ 1^{\circ}$, XIII).

O Código Florestal Federal, Lei 4.771, data de 1965, período em que vigia outra Constituição, com outros fundamentos axiológicos e outra estrunura federativa. Esse código sofreu alterações, mas continua em vigor. No seu artigo 27, dispõe que:

Art. 27-É proibido o uso de fogo nas flotestas e demais formas de vegetação.

Parágrafo único. Se peculiaridades locais ou regionais justificarem o emprego do fogo em práticas agropastoris ou florestais, a permissão será estabelecida em ato do Poder Público, circunscrevendo as áreas e estabelecendo normas de precaução.

Em 1992, o Estado do RS edirou seu próprio Código Florestal, seguindo a orientação disposta no Ato das Disposições Transitótias da Constituição (ADCT). No entanto, desde esta edição, diversos segmentos sociais mostratam-se insatisfeitos com as vedações por ele impostas e se insurgiram contra a sua aplicação. Entre estes segmentos, destacaramse os dos pecuaristas e mais recentemente, de agticultores com pouca terra. Em alguns municípios foram elaboradas e aprovadas leis com base no interesse local, distanciandose dos comandos normativos contidos na Constituição Estadual (CE) e no Código Florestal.

\footnotetext{
'Sobre lei arbitrária sugerimos a leitura de DANTAS, F. C. de San Tiago. Igualdade perante a lei e due process of law: Contribuição ao estudo da linitaçăo constitucional do Poder Legislativo. http: // www.planalto.gov.br/ccivil_03/revista/Rev_32/panteăo_32.htm//. Acesso em: 02/09/2002.
} 
Tal movimento culminou com a elaboração de uma Emenda que alterou sensivelmente a Constituição estadual. A bancada majoritária na Assembléia Legislativa adotou o seguinte raciocínio: se a Constituição permite as queimadas controladas e está acima do sistema infraconstitucional, então não podemos nos opor a ela. Seguindo esse raciocinio e, ainda, baseados na decisões jurisprudenciais a eles desfavoráveis, optaram pela tentativa de mudança na Lei Maior.

Contudo, há um sistema de valores que "tatua" a Constituição. Ele não pode sequer ser altetado por reformas constitucionais, pois está centrado no campo das limitações explícitas (cláusulas pétreas) e implícitas, decisão política fundamental do Estado. No caso gaúcho, o constituinte de 1989 optou pela tealização da preservação do meio ambiente e adotou expressamente como uma das medidas possíveis combater as queimadas. Essas ações podem ser consideradas como instrumentos para concretizar o direito ao meio ambiente equilibrado. $\mathrm{E}$ isso constituiu uma decisão política fundamental. Ctiou então uma norma mais restritiva que orientou o legislador estadual na elaboração do Código Florestal estadual. Por sua vez, esse diploma legal, inspirado nesse fundamento axiológico, possibilitou unicamente a realização das queimadas em caso de controle e eliminação de pragas e doenças, como forma de tratamento fitossanitário, desde que não seja de forma cont́nua e mediante licença do órgão florestal competente.

Senão fosse a existência do artigo 251 , talvez pudéssemos pensar na possibilidade de o Estado autorizar a realização de queimadas controladas. Elas dependeriam, porérn, da apreciação da área propriamente dita e da autorização do órgão estadual competente (o impacto não é meramente local) e, em determinados casos, inclusive de EIA/RMA, somado isso à apreciação de inúmeros princípios que regem o direito ambiental. Mas essa não foi a opção do constituinte estadual, que preferiu combater as queimadas. Assim, nenbuma norma infraconstitucional, sequer uma reforma constitucional paderia subvertertalentendimento.

Que lógica é essa? Por quem os sinos dobram?

Para tentar responder essa questão, organizamos o texto em cinco partes além desta. Na primeira e na segunda é feita uma cronologia das proposições apresentadas na Assembléia Legislativa do Rio Grande do Sul sobre as queimadas. Na terceira, é descrita a atuação do Ministério Público sobre a tentativa de alteração da Constituição Estadual. A quarta comenta a jurisprudência sobre o tema. A última parte apresenta algumas conclusões.

\section{Sob fogo cruzado: as queimadas na arena parlamentar gaúcha}

A promulgação da Emenda Constitucional (EC) $\mathrm{n}^{\circ} 32 \mathrm{em}$ julho de 2002 concluiu um importante processo de debate sobre a legislação ambiental do Rio Grande do Sul. Através dela for alterado o dispositivo que incumbia o Estado de combater as queimadas e responsabilizar o usuário da terra pelas suas conseqüências: 
Art. 251. Todos têm direito ao meio ambiente ecologicamente equilibrado, impondose ao Poder Público e à coletividade o dever de defendê-lo, preservá-lo e restaurá-lo para as presentes e futuras gerações, cabendo a todos exigir do Poder Público a adoção de medidas nesse sentido.

$\$ 1^{\circ}$ Para assegurar a efetividade desse direito, o Estado desenvolverá ações permanentes de proteção, restauração e fiscalizaçâo do meio ambiente, incumbindo-lhe, primordialmente:

I- prevenir, combater e controlar a poluição em qualquer de suas formas;

II - preservar e restaurar os processos ecológicos essenciais, obras e monumentos artísticos, históricos e naturais, e prover o manejo ecológico das espécies e ecossistemas, definindo em lei os espaços territoriais a serem protegidos; (...)

VII - proteger a flora, a fauna e a paisagem natural, vedadas as práticas que coloquem em risco sua função ecológica e paisagística, provoquem extinção de espécie ou submetam os animais à crueldade;

VIII - definir critérios ecológicos em todos os níveis do planejamento político, social e econômico; (...)

$\mathrm{XI}$ - promover o manejo ecológico dos solos, respeitando sua vocação, quanto à capacidade de uso; (...)

XIII-combater as queimadas responsabilizando o usuário da terra por suas conseqüiências. (grifamos)

A nova redação passou a estabelecer que incumbe ao Estado:

XIII-combater as queimadas, ressalvada a hipótese de que, se peculiaridades locais justificarem o emprego do fogo em práticas agropastoris ou florestais, ocorra permissão estabelecida em ato do poder público municipal, estadual ou federal, circunscrevendo as áreas e estabelecendo normas de precaução. (grifamos)

Deputados de vários partidos comemoraram a aptovação da EC, assim como entidades representativas de produtores rutais e de associações de municípios. O Governo do Estado, através do Secretário Estadual do Meio Ambiente, considerou-a como um verdadeiro retrocesso na defesa do meio ambiente ${ }^{2}$. Este entendimento que foi reiterado pela Conferência Estadual do Meio Ambiente (CONFEMA 2002), que aprovou uma moção de repúdio contra as queimadas ${ }^{3}$.

\footnotetext{
"Wegislativo aprova queinadas controladas". Correio do Povo, Porto Alegre, 26.06.2002. Geral, p. 5.

${ }^{3}$ Ver a este respeito: "Confema pede fim da caça no RS". Correio do Povo, Porro Alegre, 16.09.2002.
} 


\section{Da Constituição Estadual à Emenda Constitucional 32/02: uma cronologia}

O ADT da Constituição do Rio Grande do Sul de 1989, prevê em seu artigo 40 a edição de dois Códigos Estaduais nos quais o uso do fogo poderia ser abordado, o do Meio Ambiente e o Florestal.

O Código Estadual do Meio Ambiente começou a ser debatido pela Assembléia Legislativa a partir dos Projetos de Lei (PLs) $n^{\circ} 177 / 91$ e $n^{\circ} 206 / 92$, de autoria do deputado Ivar Pavan (Partido dos Trabalhadores - PT).

O primeito projeto proibiu no attigo 58 a promoção de queimadas em três situações: nas unidades de proteção ambiental, nas zonas de proteção ambiental e nas terras de propriedade do Estado ou dos Municipios. No artigo 59, estabeleceu a responsabilidade dos proprietários adotarem medidas preventivas eficazes contra a propagação de incêndios a partir de queimadas em propriedades privadas. O segundo projeto manteve, nos artigos 47 e 48 , a tedação proposta anteriormentc, incluindo a proibição da promoção de queimadas também para as restevas de lavouras.

A partir de 1994 as propostas para o Código Estadual do Meio Ambiente passaram a set de iniciativa da Comissão Permanente de Saúde e Meio Ambiente. Naquele ano, foi protocolado o $\mathrm{PL} n^{\circ} 400$, que no seu artigo 60 vedava o corte raso das florestas nativas, bem como as queimadas de campo e de qualquer outro tipo de vegetação. O projeto foi desarquivado nos anos de 1995, 1996 e 1998, mas não teuniu condições técnicas e políticas para votação em Plenário.

Em 1998, a mesma Comissão ofereceu uma nova redação ao Código através do $P L \mathrm{n}^{\circ}$ 140. Manteve, no entanto, o texto do artigo 60 da proposta anterior (agora renumerado como artigo 165) e criou um parágrafo único a ele, vedando também o uso de substâncias químicas para desidratação, sccagem ou queima de vegetação como forma de manejo de campo nativo e de florestas. O projeto foi desarquivado em 1999 e 2000, quando foi levado à votação no mês de junho.

Em Plenário, foram propostas várias emendas em relação ao artigo 165. Ao final, prevaleceu o acotdo entre os lideres partidários de todas as bancadas favorável à emenda, de iniciativa da Bancada do Partido Progressista Brasileiro (PPB), que propôs a supressão deste artigo. A justificativa do autor para a emenda argumentou que a vedação da queima de campo contraria "prática de manejo agropastoril apoiada em abalizadas opiniões técnicas e consagração pelo uso multissecular, sem qualquer degradação das pastagens da região do Planalto do Nordeste do Estado."

Dessa forma, a Lei $n^{\circ} 11.520 / 00$, que instituiu o Código Estadual do Meio Ambiente, não contém dispositivos específicos sobre as queimadas, a não ser o artigo 23, que autoriza o Poder Executivo a firmar convênios com entidades públicas $\mathrm{e}$ privadas para auxiliarem na preservação do ambiente natural e na orientação de entidades de agricultores e pecuaristas sobre as queimadas em geral. 
Cabe, então, ao Código Estadual Florestal (Lei n $\left.{ }^{\circ} 9.519\right)$ as principais normas sobre o tema. Foi instituído em 1992, a partir do PL $n^{\circ} 85 / 91$, de autoria do deputado Francisco Turra (PDS, atual $\mathrm{PPB}$ ), cuja redação original previa a proibição do uso do fogo nas atividades agtopastoris e florestais (art. 52). Permitia a sua utilização para limpeza e manejo em áreas de florestas, atividades agropastoris e demais formas de vegetação mediante autorização da autoridade florestal competente nos casos de tratamento fitossanitário, observadas normas, critérios e garantias de controle (art. 53). A ptoposta incluia ainda dois artigos para prevenção e extinção de incêndios florestais (arts. 54 e 55) e um capítulo específico sobre as atribuições dos municípios (art. 24). Por esse dispositivo, a política florestal municipal deveria ajustar-se às disposições do Código, priorizando, ente outros aspectos, o controle, a fiscalização e a proteção do ambiente, de forma complementar e conjunta com os organismos federais e estaduais (inciso II).

Não houve acordo ente as bancadas sobre as atribuições dos municípios, entre outros aspectos. O substitutivo apresentado pelo autor do Projeto foi aprovado por unanimidade pelos deputados em dezembro de 1991 . Em seu artigo 28, proibiu o uso do fogo ou queimada nas florestas e demais formas de vegetação natural, e nos dois parágrafos seguintes possibilitou esse uso, de forma descontínua, em caso de controle e eliminação de pragas e doenças como prática de tratamento fitossanitário:

Art. 28- É proibido o uso do fogo ou queimadas nas florestas e demajs formas de vegetação natural.

$\$ 1^{\circ}$ - Em caso de controle e eliminação de pragas e doenças, como forma de tratamento fitossanitátia o uso de fogo, desde que não seja de forma contínua, dependetá de licença do órgão florestal competente.

$\$ 2^{\circ}$ - No caso previsto no $\$ 1^{\circ}$, o órgão floresral competente deverá difundir critérios e normas de queima controlada, assim como campanha de esclarecimento de combate a incêndios.

A lei incumbiu ainda o órgão florestal competente de licenciar o uso do fogo e difundir critérios e normas de queima controlada, assim como realizar campanha de combate a incêndios.

Em 1998, o PL n ${ }^{\circ} 287$, de autoria do deputado Kalil Sehbe (Partido Democrático Trabalhista - PDT), propôs a supressão do art. 28 do Código Florestal Estadual e dos seus parágrafos $1^{\circ}$ e $2^{\circ}$. Esse projeto foi reapresentado $\mathrm{cm} 1999$ e 2000 , mas não foi votado pelo Plenário. O entendimento do autor cra que, uma vez aprovada a sua proposta, o tema seria remetido exclusivamente ao Código Florestal Federal, em especial ao seu artigo 27.

Em agosto de 1999 , o deputado João Osório (Partido do Movimento Democrático Brasileiro - PMDB) protocolou o PL ñ 189 , que mantinha a proibição do uso do fogo, mas permitia o seu emprego "como meio de controle e eliminação de pragas e doenças, como forma de tratamento fitossanitário, bem como em áreas já 
utilizadas anteriormente para lavoura, se as peculiaridades locais ou regionais assin justificarem, e mediante permissão de órgão do poder público municipal".

A justificativa do projeto destacou o uso do fogo como prática necessária associada à recomendação técnica da prática de pousio para conservação do solo. Este tippo de ação auxiliaria a produção e a manutenção das famílias dos pequenos produtores.

$\mathrm{O}$ autor enfatizou também as atribuições do Poder Público Municipal para permitir o uso do fogo e credenciar técnicos para emitir os laudos necessários. Segundo o autor, este poder estaria mais capacitado em razão da proximidade geográfica e da disponibilidade de recursos humanos e institucionais para proceder à identificação das características locais, do cumprimento das normas previstas e da sua fiscalização.

O projeto foi aprovado pelo Plenário em maio de 2000 , com uma emenda apresentada pelo deputado Germano Bonow, do Parrido da Frente Liberal (PFL). A emenda estendeu ao Poder Público estadual a atribuição de permitir o uso do fogo como forma de tratamento fitossanitário nas condições previstas na lei e credenciar técnicos competentes para a emissão de laudo para essa finalidade.

O veto total do Poder Executivo ao PL $n^{\circ} 189$ baseou-se em razões de ordem constitucional, legal e de defesa do interesse público. O Governador do Estado, Olívio Dutra (PT) considerou, enrre ourros aspecros, que o projeto aprovado teria o "condão de provocar o uso indiscriminado e descontrolado do fogo, abrindo a possibilidade à inadequada municipalização da proteção ambiental, sem a previsão de instrumentos de participação, sem a fixação de critérios técnicos adequados ou mesmo sem a verificação da capacidade dos municípios de eferuarem a vigilância necessária na prática da queimada". Segundo o Governador, "diversos estudos comprovam que o uso indiscriminado do fogo e de queimadas na vegetação diminui as condições de proteção e manutenção da biodiversidade de espécies da fauna e da flora, aumenta a emissão de gases na atmosfera, eleva a temperatura da superfície e altera os processos microbiológicos no solo prejudicando a sua estrutura e fertilidade e aumentando o risco de erosão. Ademais o fogo desconrrolado, em suas diversas modalidades, traz perigos a comunidade, podendo destruir habitações, plantaçōes, ctiações, estações de telecomunicações, além de causas o desligamento de linhas de transmissão e distribuição de energia elétrica e o comprometimento do transporte aéreo, todoviário e ferroviário, enrre outros. Salientou ainda que a proposta não contemplava qualquer tipo de preocupação com a vegetação existente no local, o que poderia colocar em tisco até a Mata Atlântica ${ }^{4}$.

"O próprio deputado João Osório, autor do $\mathrm{PL} \mathrm{n}^{\circ} 189$, reconheceu parte dos argumentos do veto, protocolando em seguida o PL $n^{\circ} 190 / 00$, corrigindo a redaçăo dada pela Lei $n^{\circ} 11.498$. Essa nova redaçāo permitia o uso do fogo somente em áreas de capoeira, concejuada pelo Código Florestal Estadual, desde que já utilizadas anteriomente como lavoura. Ela manteve, porém, a atribuiçào dos munićpios para permitir o uso do fogo. Procurou assim, excluir a possibilidade legal de atingir as florestas. 
O veto foi rejeitado por 30 votos contra 12 . Em seguida, foi promulgada como Lei $\mathrm{n}^{\circ}$ 11.498, de 04 de julho de 2000. Em seguida, o Pleno do Tribunal de Justiça do Estado considerou inconstitucional esta Lei, conforme será descrito adiante neste texto.

Em 2001, o deputado Frederico Antunes (PPB) apresentou o PL n ${ }^{\circ} 322$, que resgatou em grande parte o conteúdo de uma emenda prejudicada por ocasião da votação do Código Estadual do Meio Ambiente. Seu objerivo foi o de "harmonizar o atual confito existente entre a tepressão ao uso do fogo em campos nativos e a necessidade dessa ferramenta como inanejo para a obtenção de proteína animal". Nesse intuito, propôs alterar o artigo 28 do Código Florestal e permiur o emprego do fogo, mediante a queima controlada, como técnica de manejo em atividades agropastoris, observadas as normas e condições contidas na legislação federal e os critérios de zoneamento territorial do Estado nos aspectos de solo, topografia e cobertura vegetal.

A proposição define queima controlada como o "emprego do fogo de forma adequada e responsável pelo produtor, observando a época, condições climáticas, limites de áreas e preservação das áreas relevantes para manutenção da diversidade dos sistemas". Também estabelece a responsabilidade dos órgãos governamentais para inplantarem e incentivarem programas alternativos com vistas à redução gradativa do uso do fogo e prevê um período de cinco anos para implantação desses programas.

A partir de 2001, foram protocoladas duas Propostas de Emenda à Constituição (PEC). Ambas trataram com igual teor a mudança do inciso XIII do parágrafo $1^{\circ}$ do artigo 251, telativo ao combate das queimadas. A primeira delas, de autoria do deputado Francisco Appio (PPB) e outros 21 deputados, recebeu o número 113. Foi autuada em junho de 2001 e submetida à votação em Plenário em dezemhto do mesmo ano, quando obteve 29 votos favoráveis e 12 votos contrários. Foi rejeitada por não atingir os 33 votos exigidos pelo art. 58 , parágrafo $2^{\circ}$ da Constituição (ttês quintos do total de deputados).

A segunda PEC, de autoria do deputado Francisco Appio (PPB) e mais 31 deputados recebeu o número 119. Foi autuada em março de 2002 e submetida à votação em Plenátio em junho do mesmo ano. Foi aceita em primeiro turno com 39 votos favoráveis e 8 votos contrários, e aprovada em segundo turno com 38 votos favoráveis e 13 votos contrários.

A justificativa da Proposta de Emenda ressaltou que o texto constitucional criava restriçōes ao emprego do fogo previsto pelo artigo 27 do Código Florestal Federal. Em especial, impedia que os municípios da região Nordeste do Planalto do Estado legislassem sobre esta prática, considerada consagrada e adequada às peculiaridades locais e regionais ${ }^{5}$.

\footnotetext{
${ }^{5}$ Desde a edição do Código Florestnl Estadual, o Tribunal de Justiça do Río Grande do Sul considerou inconstitucionais diversas leis municipais que tratavam autorização da queimada de campo nativo. A maioria delas foi aprovada de $1994 \mathrm{em}$ diante. Rntre estras normas, destacam-se as de André da Rocha, São Francisco de Paula e Sâo José dos Ausentes (julgadas em 1995), Lagoa Vermelha (1996) e Jaguirana (2000), todos muricípios da região Nordeste do Estado.
} 
A Emenda Constitucional promulgada tem a seguinte redação:

XIII-combater as queimadas, ressalvada a hipótese de que, se peculiaridades locais justificarem o emprego do fogo em práticas agropastoris ou florestais, ocor ra permissão estabelecida em ato do poder público municipal, estadual ou federal, circunscrevendo as áreas e estabelecendo normas de precaựão." (gtifamos)

Depois da promulgação da EC foram protocolados dois projetos que tinham como objetivo regulamentá-la: o PL 213/02, do dep. João Osório (PMDB) e o PL 225/02, do Poder Executivo. O Governo do Estado entendeu que à mudança na Constituição deveria corresponder a alteração do art. 28 do Código florestal e por esta razão, não editou qualquer norma que a regulamentasse.

Em sintese, podemos verificar que desde a edição da $\mathrm{CE}$, foram várias as tentativas de alteração da legislação relativa às florestas. Ao longo dos anos, elas foram encampadas por diferentes partidos com diversas argumentações. Progtessivamente, fozam alcançadas as condições políticas e os votos necessátios para viabilizar a aprovação das modificações propostas.

O apoio a estas proposições cresceu principalmente após o reforço do argumento que procurava contrapor o interesse ambiental ao interesse social de determinadas tegiões geográficas e certos grupos, especialmente dos agricultores com pouca terta ou pouca tenda.

Também contribuiu decisivamente para estas aprovações a formação de um bloco de oposição ao Governo do Estado, que se manifestou contrário às proposições que tornavam menos rígidas as restrições às queimadas. Estes parlamentates procuraram, de uma forma geral, caracterizar supostas arbitrariedades do governo cm relação à fiscalização e uma suposta omissão frente aos efeiros econômicos e sociais da crise na agropecuária.

A formação deste bloco majoritário foi freqüente durante todo o periodo legislativo e suas origens extrapolam os debates a respeito dos temas ambientais.

\section{A Emenda Constitucional 32/02 e a atuação do Ministério Público}

O Ministério Público do Rio Grande do Sul (MPRS) ajuizou Ação Direta de Inconstirucionalidade (ADIN) sobre a $\mathrm{EC}^{\circ} 32$. O Tribunal de Justiça do Estado (TJRS) julgou procedente o pedido liminar ${ }^{7}$ para sustar os efeitos da mesma, o que felizmente denota uma maior aproximação do magistrado em relação ao direito ambiental e da crescente conscientização do tribunal gaúcho no que diz respeito à preservação ambiental.

\footnotetext{
"Agradecemos a assessora jurídica do MPRS, Paula Lavkatti, e à Dra. Sívia Cappelli, procuradora de justiça do RS, pelo envio de cópia da ADIN ajuizada pelo MPRS em matéria de quemadas.

"Sobre a decisão final enanado do Tribunal Pleno existe outro artigo elaborado, ainda inédito.
} 
A ADIN constitui um dos instrumentos de efetivação dos direitos fundamentais. Eis aqui a aproximação do direito instrumental e direito material, atenuando-se suas linhas divisórias e aptoximando-os. No presente caso, com a aprovação da Emenda Constitucional, não restou alternativa senão $\circ$ ajuizamento desse instrumento processual-constitucional para ver-se garantida a preservação do direito ao meio ambiente equilibrado enquanto direito fundamental. Notese: tal emenda feriu as limitações materiais constitucionais explícitas - as cláusulas pétreas -, pois o direito ao meio ambiente ecologicamente equilibrado, direito de terceira geração, é essencial à realização da dignidade humana (um dos fundamentos do Estado Democtático de Direito) e está intimamente ligado ao direito à vida, direito dito individual. Além disso, embora a ação não mencione, foi igualmente ferida a limitação material implícita contida na constituição, ou seja, a decisão política fundamental ${ }^{8}$.

Segundo essa decisão política fundamental, manifestada pelo Poder Constituinte, propugnounse o combate amplo das queimadas e isso não nos parece que poderia ter sido alterado via reforma constitucional, senão por uma nova constituição. Parece-nos que o processo de reforma da constituição que caracteriza a mutação constitucional não pode englobar a decisão política fundamental do Estado em ter elencado o combate das queimadas como um dos instrumentos de efetivação do direito ao meio ambicnte ecologicamente equilibtado.

Nessa ADIN ajuizada pelo Procurador-Geral de Justiça do Estado do Rio Grande do Sul (processo n 70005054010), um dos legitimados ativos para ajuizá-1a em nosso Estado, invocaram-se alguns fundamentos que caracterizariam a inconstitucionalidade da EC 32/02. Senão vejamos:

- violação dos princípios da precaução, prevenção e da proibição de tetrocesso social (art. 251 da CE e $225 \mathrm{da} \mathrm{CRFB} \mathrm{-} \mathrm{nelas} \mathrm{implicitamente} \mathrm{previstos)}$

Nesse sentido, vale transcrevermos a menção à violação do princípio do não tetrocesso social sustentado na referida ação em matéria ambiental:

(...) Por tudo o que foi exposto, pode-se afirmar que a alteração do texto da Constituição do Estado, ora combatida, é manobra de flagrante retrocesso social. Trata-se de verdadeira contravenção dos fins constitucionais, fins esses que vinculam tanto o Executivo quanto o Legislativo. Discorrendo sobre o que chama de "O princípio do não retrocesso social", assim preleciona José Joaquim Gomes Canorilho:

O princípio da proibição de retrocesso social pode formular-se assim: o núcleo essencial dos direitos sociais já realizado e efectivado através de medidas legislativas (...) deve considerat-se constitucionalmente garantido, sendo inconstitucionais quaisquer medidas estaduais que, sem a criaçào de outros esquemas alternativos ou compensatótios, se traduz na prática numa 'anulação', 'revogação' ou 'aniquilação' pura a simples desse núcleo essencial. A liberdade de conformação do legislador e inerente auto-reversibilidade têm como limite o núcleo essencial já realizado.

${ }^{8}$ Nesse sentido, v. FERRAZ (1986) e FERREIRA FILHO (1995). 
- afronta ao princípio da repartição de competências legislativas com base nos artigos $1^{\circ}, 8^{\circ}$ e 10 da Constituição do Estado.

Esta foi a manifestação do MPRS:

As normas constitucionais que encerram princípios presumem-se implícitas nas Constituições Estaduais e nas Leis Orgânicas Municipais. A simetria é inafastável, pois a unidade política, no caso, o Estado, não pode conflitar com o ordenamento jurídico fundamental. Sendo assim, não poderia a Assembléia Legislativa promulgar tex to normativo sobre natéria relativa ao meio ambiente em sentido diverso do que o fez a União, a teor dos arts. 23, VI, e 24, VI, da Constituição da República. Havendo competência legislativa concorrente para tratar do assunto, descabe ao Estado autorizar o Municipio a emitir licenças ambientais para práticas cuja repercussão ambiental ultrapassa, em tese, os danos locais, visto que à União incumbe fixar normas gerais sobre o tema e, em o fazendo, regulou expressamente a matéria.

Assim procedendo, incorreu o Legislador Estadual em afronta ao art. $1^{\circ}$, caput, da Lei Maior Estadual, segundo o qual o Estado do Rio Grande do Sul, nos limites de sua autonomia e competência, adota "os princípios fundamentais e os direitos individuais, coletivos, sociais e politicos universalmente consagrados e reconhecidos pela Constituição Federal, a todas as pessoas no âmbito de seu território."

No caso vertente, ocorre clara colidência entre o regtamento estadual ora impugnado e o Decreto Federal $n^{\circ} 2.661 / 98$, que trata da queima controlada. Isso porque este ato normativo prevê a atuação do SISNAMA (Sistema Nacional do Meio Ambiente) como órgão licenciador daquela atividade, enquanto o atual inciso XIII do $\$ 1^{\circ}$ do art. 251 da Carta Estadual outorga ao Município o poder de autorizar a queima de campos, quando é certo, ademais, que a Resolução $\mathrm{n}^{\circ} 237 / 97$ do CONAMA reserva, em seu art. $6^{\circ}$, ao órgão ambiental municipal - ouvidos os órgãos competentes da União, Estados e Distrito Federal, quando couber-, apenas olicenciamento ambiental de empreendimentos e atividades de impacto ambiental local e outras que thes forem delegadas pelo Estado por instrumento legal ou convênio, hipóteses essas estranhas aos autos.

Ademais, a Lei Federal ${ }^{\circ}$ 6.938/81 já disciplinava a matéria, estabelecendo, em seu att. 10, caput, a necessidade de licenciamento ambiental - a ser concedido por "órgão estadual competente" - para atividades que ponham em risco o meio ambiente. Dessa forma, havendo legislação federal editada em consonância com o arr. 24 da CF, afigura-se inconstitucional o texto normativo impugnado.

Como ensina Paulo de Bessa Antunes(2002), "no momento em que passe a existir legislação federal sobre normais gerais, a legislação estadual, naquilo que contrariar a notma federal, perde eficácia”. E a Emenda Constitucional $n^{\circ} 32 / 02$, a possibilitar que os Municípios venham a emitir licenciamentos para práticas potencialmente causadoras de danos ambientais regionais ou nacionais, claramenre afrontou a já existente sobre o assunto. Note-se que a norma atacada utiliza a conjunção "ou" para apontar os órgãos responsáveis pela enissão da autorização necessária ao emprego do fogo, significando, com isso, que também ao Muricípio 
é outorgada atribuição bastante para proceder à avaliação das justificativas apresentadas para o referido procedimento.

Registre-se que a queima de campo ou de florestas jamais caracterizará atividade de impacto local, porquanto o monóxido de carbono por ela irradiado ultrapassa a circunscrição territorial do município que eventualmente permitiu a queimada, além de causar outras conseqüências nocivas ao ecossistema, tais como a qucima de banbados e de nascentes. $O$ licenciamento em quesião, portanto, não poderia ocorrer na esfera municipal, seja porque a atividade não é de impacto meramente local, seja porque a legislą̧ão federal mencionada atribui a órgão estadual a função autorizadora.

-tecnologia inapropriada e ausência de interesse público:

Segundo o MP:

(...) o procedimento da queimada, com certeza, não se inclui dentre as tecnologias apropriadas à recuperação e conservação do solo, referidas no caput do art. 197 supramencionado. Tampouco atende ao interesse público de que trata o dispostivo legal. Com bem disse o ilustre Desembargador Talai Djalma Selistre referindo-se à norma autorizadora do uso do fogo, - no voto proferido no julgamento da $\mathrm{ADIn} n^{\circ} 594123739$, «a regra pode proteger a produção, jamais o meio ambiente«.

E adiante:

Por outro lado, a Lei n 11.520, de 03 de agosto de 2000, que institui o Código Estadual do Meio Ambiente, prevê, em seu ar. 197, ser "dever do Estado e dos municípios estimular, incentivar e coordenar a geraçăo e difusão de tecnologias apropriadas à recuperação e conservação do solo, segundo a sua capacidade de produção". E, ainda, no tespectivo patágrafo segundo, consta que "o interesse público sempre prevalecerá no uso, recuperação e conservação do solo e na resolução de conflitos referentes a sua utilização independentemente das divisas ou limites de propriedades ou do fato do usuário ser proprietário, arrendatário, meeiro, posseiro, parceito, que faça uso da terra sob qualquer forma, processos e técricas referidos no 'caput'.

\section{As queimadas na jurisprudência do TJRS}

Em pesquisa no site de jurisprudência do TJRS, encontramos onze decisões jurisprudenciais a respeito de queimadas, além da ADIN a respeito da Emenda Constirucional que versa sobre as queimadas recentemente ajuizada. Nessa decisão, aliás, Algumas tratam da realização de queimadas sem a licença do órgão competente, nas quais se discute a existência de dano", imputando-se a responsabilidade civil para a sua reparação.

\footnotetext{
"Essas decisōes datam de 1999 e 2000. Senão vejamos: Apelação civel n. 70001356997, Relator Rosa Rodrigues, data do julganento: 9.11.00; Agravo de instrumento n. 599454584, Refator Adão Cassiano, data do julgamento: 28.10.99; Apelação cível n. 70003962628, Relator Vasco Della Giustina, data do julgamento: 15.05.2002; Agtavo de instrumento n. 399453578, Relator: Antônio Pereira, data do julgamento: 28.06 .99 . XIII- combater as quemadas, xesponsabilizando o ustário da terra por suas conseqüencias".
} 
Senão vejamos, v.g., um dos casos julgados. Eis a ementa:

RECURSO: APELAÇÃO CÍVEL - NÚMERO:70003962628. $4^{a}$ Câmara Cível. RELATOR:VASCO DELLA GIUSTINA. DATA DO JULGAMENTO: 15.05.02. PROVIMEN'TO PARCIAL. Apelante: Clavio Varela. Apelado: Ministério Público. EMENTA: Ação CIVIL PUBLICA. BOM JESUS. QUEIMADAS EM PASTAGENS NATIVAS. PRELIMINARES REJEITADAS. LEIS ESTADUAIS NS 9519/92 E 11.948/ 2000. ADIN. COMPROVAGAO DO ATO LESIVO AO MEIO AMBIEN'TE. RESPONSABILIDADE CIVIL. INDENIZAÇÃO DEVIDA, COM MODIFICAÇÃO DO VALOR. APELO PARCIALMENTE PROVIDO.

Nesse julgado, os desembargadores apreciaram a questão do quantum devido pela realização de queimadas em agosto de 1997, sem autorização da autoridade competente. Na ação civil pública alegounsc a provocação de danos ao solo, à flora, à fauna silvestre, à atmosfera, comprometendo a qualidade de vida e saúde da população. Houve a condenação no valor de $\mathrm{R} \$ 14.850,00$, referente aos danos ambientais causados, o qual seria revertido para o fundo de que trata o att. 13 da Lei 7.347/85. O demandado foi condenado ao pagamento das custas processuais. $O$ demandado recorreu, asseverando que a prática de queimadas seria uma forma de manejo agropastoril, entre outros fundamentos.

No voto dos desembargadores foram destacados alguns aspectos:

a) leis municipais que autorizaram queimadas em campos foram objeto de ADINs no Tribunal de Justiça, tendo sido julgadas inconstitucionais (ADINs 94139669 e 594134.009);

b) função social da propriedade. Eis trecho do voto do Desembargador Wellington Pacheco:

(...) Função social é um plus à função privada, do que se conclui que o proprietário tem uma obrigação implícita para exercer o seu múnus de proprietário. Essa função social - diz a ptópria Constituição -, quando se trata da propriedade rural, ć cumprida quando a propriedade atende simultaneamente a critérios e graus de exigências estabelecidos em lei. Há os seguintes requisitos: utilização adequada dos recursos natukais disponiveis e preservação do meio ambiente.

Então, paraque alguém seja tido dentro do nozo conceito de proprietánio no Brasil, há necexsidade deque ele utilize a propriedade de forma adequada, respeitando os recursos naturais disponizeis, epreserve o meio ambiente

c) papel do juiz da interpretação do caso, conflito entre direitos fundamentais e comprometimento dos ecossistemas. Eis trecho do voto do Desembargador Araken de Assis:

De acordo com a teoria corrente, o Juiz decidirá em nome dos princípios constitucionais, e conforme os valores praticados pela sociedade em determinado momento; porém, freqüentemente acontece que, em vez de captar tais valores, sabe-se lá por que instrumen to técnico, utiliza o julgador os seus próprios valores. 
Por isso, no caso há lei que resolve o problema. Se mostra-se desejável, ou não, outra disciplina legal . e há, conforme acabei de ler, vários trabalhos, um do Sindicato Rural de Esmeralda, acerca da queimada, e outras intervençóes do Dr. Varella - é outro problema. Aqui se diz que o fogo não degrada o solo, porque, principalmente a favor do vento, ele é muito rápido, a temperatura é alta, mas consome só a vegetação rala e passa adiante. Parece-me que tal noção contraria o senso comum, se é que ele se aplica ao assunto. À luz dos elementos dos autos, melhor se revela explicação do Ministério Público, que diz, com alguma graça e bom estilo, que a queimada destrói tudo o que está no seu caminho: vegetação nativa, mudas de árvores, ninhos de pássaros e outros animais. Fico imaginando se as cobras sobrevivem às queimadas... É óbvio que não. Eisto já bastaria para recomendar a proscrição das queimadas.

d) dificuldade de fixar-se um valor a título de indenização - Aliás, um dado próprio de todas as questões que envolvem a matéria ambiental. Afinal, como fixar um valor econônico para um leito de um rio, pata um dado ecossistema etc? Quanto valem x ninhos de passarinhos, supondo que aquele periodo é um período de acasalamento? Quanto valem $\mathrm{x}$ cobras corais para um dado ecossistema?

Em outras decisões jurisprudenciais, encontramos a discussão a respeito da competência legislativa ambiental. Primeiramente, deparamo-nos com o conflito competência municipal versus competência estadual e, num segundo momento, os limites da competência legislativa estadual. Percebemos nitidamente a pressão do lobby de agricultores e prefeitos que culminou, devido às infrutíferas tentativas de ampliação dos casos da realização de queimadas, na alteração da própria constituição estadual.

a) competência legislativa nunicipal versus competência legislativa estadual - Em todos os casos, não foi reconhecida a possibilidade de os municípios legislarem sobre a proteção das florestas no intuito de reduzirem os comandos proibitivos do Código Florestal do RS. Tal entendimento acaba seguindo o entendimento doutrinário de que os entes da federação podem maximizar a esfera normativa proibitiva em prol da proteção do meio ambiente, embora em nenhuma das decisões expressamente faça-se menção a tal entendimento. É bem verdade que a maior parte dos tribunais estaduais propendem a tal orientação doutrinária, como é o caso gaúcho.

Vejamos as ementas das ADINs nas quais apurou-se o conflito de competências entre municípios e o Estado do RS:

EMENTA: AÇÃO DIRETA DE INCONSTITUCIONALIDADE. QUEIMADAS. LEGISLAÇÃO MUNICIPAL QUE AUTORIZA QUEIMADA DE CAMPOS E/OU FLORESTAS NATIVAS. QUEDA EIVADA DE INCONSTITUCIONALIDADE FORMAL E MATERIAL FRENTE A CARTA ESTATUAL. JULGARAM PROCEDENTE A AÇÃO. (ADIN. 594139669, Relator Nelson Oscar de Souza. Data de julgamento: 15/05/95) 
EMENTA: LEI MUNICIPAL AUTORIZADORA DE QUEIMADAS. SUA INCONSTITUCIONALIDADE EM FACE DO ART. 13, V, DACE, E 24, VI, DA CF, C/CO ART. 8 DA CARTA ESTADUAL. AÇÃO PROCEDENTE PARA DECLARAR INCONSTITUCIONAL A LEI N. ${ }^{\circ}$ 01/94 DO MUNICÍPIO DE MAXIMILIANO DE ALMEIDA (ADIN. 594136079, Relator José Vellinho de Lacerda, Data de Julgamento: 11/09/95).

EMENTA: QUEIMA DE CAMPOS NATIVOS. LM-1698 DE 1994 DE BOM JESUS, QUE A AUTORIZA: INCONSTITUCIONALIDADE DECLARADA. (ADIN n. 594124703, Relator Élvio Pinto, data de julgamento: 27/11/95).

EMENTA: CONSTITUCIONAL E PROCESSUAL CIVIL. INCIDENTE DE INCONSTITUCIONALIDADE. QUEIMADAS EM CAMPOS NATIVOS DE IMÓVEIS RURAIS. LEI MUNICIPAL N 4128/94 DE LAGO VERMELHA. INCONSTITUCIONALIDADE FORMAL. COMPETÊNCIA LEGISLATIVA CONCORRENTE ENTRE A UNIÃO, ESTADOS-MEMBROS E DISTRITOFEDERAL, EXCLUÍDO O MUNICÍPIO. INCONSTITUCIONALIDADE MATERIAL. NORMA QUE PERMITE A DEGRADAÇÃO DO MEIO AMBIENTE. COMPETÊNCIA PARA LEGISLAR SOBRE A PROTEÇÃO DAS FLORESTAS. (ADIN. N. 595167941, Relator Nelson Oscar de Souza, Data de julgamento: 28/10/96).

b) limites da competência legislativa estadual - A ADIN. 70001436658, julgada em 15.02.2001, deu pela inconstitucionalidade da Lei Estadual 11.948, de 04.07.2000. Ocorte que essa lé ampliou os casos de utilização de fogo e queimadas nas florestas e demais formas de vegetação natural, possibilitando o uso de fogo nas áreas já anteriormente utilizadas para lavoura e em campos nativos, como técnica de manejo agropastoril, mediante autorização do Poder Público Estadual e Municipal. Em verdade, o nosso Código Florestal estadual nunca permitu as queimadas. Abriu exceção para os casos de tratamento firossanitário, ou seja, para o controle e eliminação de pragas ou doenças, e desde que não seja de forma contínua, dependendo de autorização do órgão florestal competente. Na fundamentação, sustentou-se a ofensa aos artigos $13, \mathrm{~V}$, e artigo $251, \$ 1^{\circ}$, I, II, VII e XIII, da Constiruição Estadual de $1989^{1010}$ Art. 13, V: "É comperência do Município, além da prevista na Constituição Federal e ressalvada a do Estado: V- promover a proteção ambiental, preservando os mananciais e coibindo práticas que ponham em risco a função ecológica da fauna e da flora, provoquem a extinção da espécic ou submetam os animais a crueldade"

Art. $251, \$ 1^{\circ}$ : Para assegurar a efetividade desse direito, o Estado desenvolverá ações permanentes de proteção, restauração e fiscalização do meio ambiente, incumbindo-lhe, primordialmente:

I-prevenit, combater e controlat a poluição e a erosão em qualquer de suas fotmas;

II - preservar e restaurar os processos ecológicos essenciais, obras e monumentos artísticos, históticos e naturais, e prover o manejo ecológico das espécies e ecossistemas, definindo em lei os espaços territoriais a serem protegidos (...); 
VII - proteger a flota, a fauna e a paisagem natural, vedadas as práticas que coloquem em risco sua função ecológica e paisagística, provoquem extinção de espécie ou submetam os animais a crueldade $(\ldots)$;

\section{CONCLUSÃO}

1. Apesar de o Código Florestal ter entrado en vigor em 1992 proibindo a prática das queimadas, diversos segmentos nas áreas rurais não obedeceram aos seus preceitos ou criatam leis municipais para afastar-se o seu impacto em nível municipal. Basearam-se, para isso, na comperência legislativa municipal, dito "interesse local". Além disso, em 2000, edita-se a lei estadual, julgada inconstitucional, e, finalmente, em 2002, faz-se a Emenda Constitucional 32/02 para permitir das queimadas.

$2 . \mathrm{O}$ apoio à flexibilização das restrições às queimadas cresceu entre os patlamentares à medida em que ela passou a ser vinculada a uma defesa de interesses determinadas regiões do Estado e de certos segmentos sociais, como os agricultores com pouca terra e/ou pouca renda. Entre os principais argumentos do bloco majoritátio formado pelos partidos de oposição ao Governo do Estado estava a suposta arbitrariedade da ação do Poder Executivo Estadual na fiscalização da prática das queimadas. Além disto, estes parlamentares argumentaram que o Estado cra omisso em relação à execução de outras medidas sociais e econômicas que deveriam proteger a vida daqueles agricultores.

3.A EC 32/02 feriu as limitações materiais constitucionais explícitas - as cláusulas pétreas - pois o direito ao meio ambiente ecologicamente equilibrado é essencial à realização da dignidade humana (um dos fundamentos do Estado Democrático de Direito) e está intimamente ligado ao direito à vida, direito dito individual. Foi igualmente ferida a limitação material implícita contida na Constituição, ou seja, a decisão política fundamental que foi combater as queimadas, disposta no artigo $251, \$ 1^{\circ}$, XIII, da Constituição Estadual.

4.A EC 32/02 também fetiu o sistema da repartição de competências em matéria ambienral, pois obrigou as municipalidades que não realizam as queimadas a suportar possíveis danos ambientais reflexos. Além disso, fixou o licenciamento em nivel municipal de uma prática cujos efeitos extrapolam a esfera local. Felizmente isso foi teconhecido em caráter liminar pelo TJRS, de maneita que foram suspensos os efeitos da mesma, o que foi mantido, por maiotia, pelo Pleno desse Tribunal.

5.A ADIN constitui um instrumento fundamental para a realização do direito ao meio ambiente equilibrado, confotme demonstra a jurisprudência, sobretudo no que diz respeito ao tema das queimadas aqui tratado. 
6.O Ministério Público no RS, como curador do meio ambiente, tem exercido um papel significativo em prol de sal preservação e conservação. Nossa Constituição Estadual prevê no artigo $95, \$ 1^{\circ}$, VIII, que as entidades de defesa do meio ambiente, entre outras, poderão ajuizar ADIN. O faro de as mesmas não exercerem esse direito demonstra a fragilidade das organizações não-governamentais frente a corporações melhor organizadas, aparelhadas e mais influentes.

7.Uma nova consciência ambiental deve ser fomentada não apenas no Poder Judiciátio e Executivo, mas no Poder Legislativo, que tem a incumbência histórica e constitucional de elaborar as leis. A cidadama deve ser exercida em prol da preservação ambiental. Uma das maneiras é justamente cobrar-se dos parlamentares a atuação com base no "due process of law", evitando-se a elaboração de leis arbitrárias. O momento atual, felizmente, é outro. É tempo da afirmação dos direitos de terceira geração, como o artigo 225 da Constituição Federal.

8. A utilização do princípio do não retrocesso social em matéria ambiental pode contribuir na efetivação do direito ao meio ambiente equilibrado. 


\section{BIBLIOGRAFIA}

\section{ARTIGOS E OBRAS JURÍDICAS}

DANTAS, F. C. de San Tiago. Igualdade perante a lei e due process of law: Contribuição ao estudo da limitação constitucional do Poder Legislativo. Disponivel em: http: // www.planalto.gov.br/ccivil_03/revista/Rev-32/panteão_32.htm. Acesso em: 02/09/ 2002.

FERrAZ, Anna Candida da Cunha. Processos Informais de mudança da Constituição. São Paulo: Max Limonad, 1986.

FERREIRA FILHO, Manoel Gonçalves. Do processo legislatvo. São Paulo: Saraiva, 1995. SILVEIRA, Patricia. Competência ambiental. Juruá: Curitiba, 2002.

\section{JORNAIS}

LEGISLATIVO aprova queimadas controladas. Correio do Povo, Porto Alegre, 26 jun. 2002. Geral, p. 5.

CONFEMA pede fim da caça no RS. Correio do Povo, Porto Alegre, 16 set. 2002, p. 7.

\section{LEGISLAÇ̃̃O}

BRASIL. Constituição da República Federativa do Brasil. 29. ed. São Paulo: Saraiva, 2002. Lei 9.795/99. Dispõe sobre a Educação ambiental, institui a Política Nacional de Educação Ambiental e dá outras providências. Disponível em: http: // www.planalro.gov.br//. Acesso em: 24/09/2002.

. Lei 4.774/65. Instirui o novo Código Florestal. Porto Alegre: Corag, 1993.

RIO GRANDE DO SUL. Constituição Estadual do Rio Grande do Sul, 1989. Porto Alegre: Assembléia Legislativa do RS, 1992.

Lei 9.519/92. Institui o Código Florestal e dá outras providências. Legislação ambiental. Brasília: Senado Federal, 1998. 